\title{
DOCUMENTOS
}

\section{La obra de arte musical: hacia una ontología de la música}

\author{
por \\ Jorge Martínez Ulloa \\ Facultad de Artes, Universidad de Chile \\ jmartinezulloa@gmail.com
}

\section{OBERTURA}

Cuando consideramos el tema de la obra de arte y su ontología, evidentemente nos estamos refiriendo a aquella pregunta o conjunto de preguntas que, maduradas en el seno de la filosofía de Martin Heidegger, remiten al tema del ser, en este caso al ser de la obra o del arte.

Fuente de aquellas reflexiones puede ser considerada toda la obra del filósofo. Sin embargo, en este breve ensayo, nos inspiramos en tres textos que parecen sentar aspectos elementales para esta reflexión: Ser y tiempo (2005b), Arte y poesía (2005a), libro que contiene dos ensayos: "El origen de la obra de arte" y "Hölderlin y la esencia de la poesía”, así como la serie de lecciones contenidas en el libro Qué significa pensar (2005c). También nos pareció interesante considerar el ensayo de Ortega y Gasset “Musicalia”, publicado en El Espectador III (Ortega: 1998), y La deshumanización del arte (Ortega: 2007), el cual en la edición de Austral Espasa Calpe contiene, además, otros ensayos de estética que también nos fueron útiles, tales como "Diálogo sobre el arte nuevo", "Sobre el punto de vista de las artes" y "El arte en presente y pretérito".

El objetivo de este ensayo es presentar la obra de arte musical en su especificidad, respecto a las otras obras del arte musical o a las obras de otras artes. Esa singularidad hace que la música, de manera más evidente que en otras artes, muestre la sustracción u ocultamiento que el ser del arte presenta para el hombre: "Todo esto sobresale cuando la obra se retrae a lo macizo y pesado de la piedra... en el sonar del sonido... Llamamos tierra a lo que la obra se retrae y a lo que hace sobresalir en este retraerse... La obra hace a la tierra ser una tierra"1. Es así como hemos llegado a formular la hipótesis de que la obra de arte musical, o más bien "lo musical", puede ser entendido como compuesto por tres estadios diferentes, los que generalmente se confunden: las ocurrencias concretas de la música, la

${ }^{1}$ Heidegger 2005c: 77 .

Revista Musical Chilena, Año LXIV, Enero-Junio, 2010, º 213, pp. 116-135 
obra, la pieza musical. Estos tres estadios obedecen a tres formas diferentes de existencia de lo musical. En sus relaciones y pertinencias se jugará lo esencial del arte en cuanto música. Para este ensayo las ocurrencias musicales serán las manifestaciones concretas de la música en cuanto fenómeno: performances musicales o conciertos, partituras, fonogramas y grabaciones, entre otros ejemplos de materialidad de la música. La pieza musical es la suma de los trazos distintivos que permiten distinguir una pieza como hecho único y específico, esto es, como unidad que preside a las ocurrencias concretas de la misma. Finalmente, obra, que nos parece pudiere ser considerada como el ser de la pieza musical. Si la pieza musical puede justamente ser pensada como un ente, una entidad, la obra es el ser de ese ente: "Al ser de la obra pertenece el establecimiento de un mundo"?

\section{TEMA UNO}

Al considerar el concepto de obra de arte que desarrolla Heidegger, notaremos, de inmediato, que la esencia de la obra de arte deriva de su origen en el arte como manifestación y que la esencia de éste depende de la pregunta por el ser del arte. Ello es evidente en los dos escritos antes citados, pese a que ambos escritos fueron redactados en dos épocas diferentes. El texto sobre la poesía es de 1937, en tanto que el artículo sobre el arte data de 1952. Es también evidente que ambos textos dependen, pese a que su autor aluda raramente a su obra anterior, de las ideas centrales expuestas en Ser y Tiempo. Si este último "puede considerarse como una ontología fundamental, los dos pequeños ensayos estéticos pueden considerarse como una ontología del arte en su más estricto sentido"3. Para Heidegger es obvio que la obra de arte es un ente: "El cuadro cuelga en la pared como un fusil de caza o un sombrero... Los cuartetos de Beethoven yacen en los anaqueles de las editoriales como las papas en las bodegas"4.

Esto podría llamar a escándalo, al considerar las obras de arte como lo haría "el guardián o la criada del museo”. Por ello el filósofo, al poner la pregunta por la obra de arte y su aspecto cósico (Dinghaft), clarifica que tomará en consideración el punto de vista del observador artístico: "Debemos, pues, tomar la obra de arte como

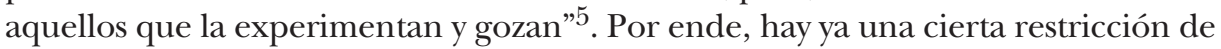
la mirada, y para esta coseidad de la obra debemos considerar una cierta actitud en el observador, lo que particularizaría dicha coseidad. Será entonces una cosa que no es la misma cosa para todos, o no de la misma manera. De esta cuestión surgirán varias consideraciones que trataremos de analizar más adelante.

Por ahora, cabe preguntarse si en esta mirada de la obra como cosa la "partitura del Cuarteto de Beethoven", citada como ejemplo en su artículo, tenga la misma naturaleza de cosa que un cuadro o una escultura, y en qué elementos difieren esos tipos de obras. En nuestra modesta opinión, las obras de arte musicales difieren de las obras pictóricas o plásticas en general. Queda en suspenso la

\footnotetext{
${ }^{2}$ Heidegger 2005c: 76.

${ }^{3}$ Heidegger 2005c: 20.

${ }^{4}$ Heidegger 2005c: 39-40.

${ }^{5}$ Heidegger 2005c: 40.
} 
pregunta por la literatura, el teatro o la danza, pero ello excedería el ámbito de este breve trabajo.

De forma análoga, la materialidad de la obra de arte musical no parece reposar en el sonido, así como la de la escultura y arquitectura reposa en la piedra. En primer lugar, porque el sonido representa una selección de variables en el interior de la sensación acústica, hecha por el auditor en forma cultural. No es directamente material, sino es el producto de una selección sensible que ya pertenece a la obra en cuanto exploración. En este caso será muy definitivo que la audición sea hecha por quien la experimenta en forma especial. Por ejemplo, en la tradición occidental la espacialidad de la señal acústica no será considerada para la fijación del sonido, como sucede en otras culturas. Además, por cuanto la partitura es sólo una ocurrencia concreta de la pieza musical denominada "Cuarteto de Beethoven". En verdad la partitura no es nada más que un programa de ejecución de dicha pieza, un conjunto de signos que contiene sólo aquellas indicaciones que pudieran ser entendidas de forma ambigua por los ejecutantes-músicos, fundamentalmente indicaciones de altura y duración, entre otras variables acústicas.

Siguiendo con el ejemplo anterior, no se dice nada en aquella partitura sobre la distancia física que debe existir entre cada músico del cuarteto, si bien ello es un dato esencial a la hora de ejecutar la obra "Cuarteto de Beethoven" como acto. Imaginad que estos músicos se diseminan en un área de 200 metros cuadrados. Obviamente ese dato, no presente en la partitura, sería de tan enormes consecuencias que no sabríamos si estamos interpretando la obra de Beethoven o una cita conceptual de John Cage o de algún otro músico experimental sobre la misma. Los datos que faltan en la partitura son integrados por los músicos, los auditores y la sociedad que saben lo que es pertinente para esa ejecución específica.

¿Debemos, entonces, poner a la sociedad en su conjunto, con todas sus prácticas, en los anaqueles? Para la época de Beethoven ese dato social era bastante evidente, sólo después de John Cage cabría preguntarse si lo sigue siendo. La pregunta por la obra no puede, por tanto, reposar sólo en la calidad material de ese ente que reposa en los anaqueles, ya que si aceptamos con el filósofo que "el sonido está en la música" y "la obra musical está en el sonido"6, la materialidad que tenemos en la partitura son signos, grafías, manchas de tinta y no sonidos. Es en la sociedad donde se produce la obra musical. Es allí donde se determina qué parte de la sensación acústica es sonido y qué parte corresponde al ruido ${ }^{7}$.

Esta última cuestión parece suficientemente clara en la exposición heideggeriana: "La obra, como tal, únicamente pertenece al reino que se abre por medio de ella. Pues el ser-obra de la obra existe y sólo en esa apertura" ${ }^{8}$. Esto quiere decir que la obra no está terminada en sí misma, sino que supone toda una red de relaciones significantes con su contexto. Justamente de esa índole de la obra de re-construir su mundo deberemos ocuparnos más adelante, cuando debamos decir, con Heidegger: "La obra de arte es en verdad una cosa confecciona-

\footnotetext{
${ }^{6}$ Heidegger 2005c: 40.

${ }^{7}$ Pensamos en una definición del tipo forma-fondo, en que la forma es recortada culturalmente y denominada sonido, en tanto que la parte desechada del fondo acústico constituye el ruido.

${ }^{8}$ Heidegger 2005c: 70.
} 


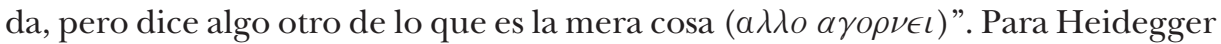
la obra hace conocer abiertamente lo otro; es alegoría y también símbolo.

La coseidad (Dingheit) de la cosa obra de arte no puede ser entonces del mismo tipo en la música que en las artes visuales. Esta coseidad no puede reposar en la partitura, si bien, en cuanto programa de ejecución, la partitura contiene datos muy útiles para producir señales acústicas pertinentes, es decir, sonidos.

La partitura puede presidir una grabación fonográfica de la pieza musical. Ambos entes serán entonces ocurrencias concretas de la misma cosa: la pieza musical "Cuarteto de Beethoven". La materialidad de ambas ocurrencias será diferente y sin embargo similar y sus auditores dirán, con razón o no, que están percibiendo "el Cuarteto de Beethoven", sin importar que estén viendo la partitura o estén escuchando una grabación. Ambas ocurrencias tendrán entonces trazos distintivos similares, que remiten a un segundo ente, cuya presencia no siempre se nota: la pieza musical.

Cuando hablemos del "Cuarteto de Beethoven" del ejemplo estaremos tratando de algo que reúne materialidades diferentes, de una cosa que remite a otras cosas, por la presencia de trazos distintivos comunes. Por ejemplo, ambas ocurrencias, la grabación y la partitura, contendrán el mismo número de notas y de duración similar, así como sus silencios y alturas relativas. Esos trazos serán la materialidad de la pieza musical, pero de todas formas la obra de arte musical como alegoría y símbolo no puede estar o residir sólo en esa materialidad.

Sabemos que la partitura y la grabación representan o remiten a ese segundo ente que, de todas formas, no puede ser considerado sólo como un modelo abstracto, pues la coseidad de sus trazos distintivos se verifica en ambas ocurrencias concretas. Ambas ocurrencias remiten a un ente unitario, la pieza musical, perceptible a través de la materialidad de sus trazos distintivos presentes en ambas ocurrencias (y en todas las otras ocurrencias que se podrán conocer como "Cuarteto de Beethoven"). Estas ocurrencias en su materialidad son cosas distintas y específicas, si bien presentan un origen común.

Todo lo anterior no agota la pregunta por la obra. Podemos pensar que la pieza musical, si bien es un ente perceptible y distinto de otros entes de la misma especie (por ejemplo, otras piezas musicales del mismo autor), depende a su vez de una verdad, de una coherencia que se transmite a través de esos trazos, pero no sólo, sino que, además, a través de todos aquellos trazos del contexto de su actuación y que no conforman el ente "pieza musical", sino que la relación de éste con su devenir.

En presencia de la pieza el auditor se preguntará por la coherencia de esos trazos, por la relación que los une y, de pronto, “... El brillo y la luminosidad de la piedra aparentemente debidas a la gracia del sol, sin embargo, hacen que se muestre la luz del día, la amplitud del cielo, lo sombrío de la noche. Su firme prominencia hace visible el espacio invisible del aire [...] El templo en pie abre un mundo y a la vez lo vuelve sobre la tierra que de tal modo aparece ella misma como el suelo nativo"9.

${ }^{9}$ Heidegger 2005c: 70-71. 
Lo mismo puede decirse de la pieza musical de Beethoven, su presencia misma hace que la vida, el devenir de la vida, el fluir de aquella cosa indefinible que llamamos tiempo se nos haga evidente: "El tiempo es el pasar de lo pasajero... El tiempo permanece en cuanto pasa..."10. Tiempo que puede aparecer, gracias a la materialidad revelada en la música en cuanto arte, en toda su consistencia y movimiento. Esta coseidad de la pieza evidentemente remite a otra naturaleza del ente y ésta es su ser "una cosa” y la vez muchas otras cosas. Creemos que esta peculiaridad del ente "pieza musical" reenvíe a su ser y este ser del ente lo denominaremos "obra". Cuando un músico o un auditor experto pregunta por la obra musical, claramente no se interesa sólo por trazos más o menos dimensionales sino que por el conjunto de ellos y su sentido, por su carácter alegórico y simbólico ${ }^{11}$. Es lo que en análisis musical se llama el sentido de la obra. Como en el templo del ejemplo evocado por Heidegger, sin embargo, es el contexto el que permite esta "iluminación de la obra sobre el mundo". Es lo que se sabe estar allí pudiendo no estar, esa distancia es la que fija el movimiento de la audición, que compromete al auditor y a la obra.

Los trazos, por así decir contextuales o extratextuales, son evidentes para el observador y determinan su percepción del ser de la pieza musical que así se revela no sólo como "un ente", sino que como "un ente en su devenir". Este ente en su devenir es el ser del ente y es lo que pensamos pueda ser definido como "la obra de arte musical".

En el caso específico del ejemplo del "Cuarteto de Beethoven", las ocurrencias concretas pueden ser las partituras de los anaqueles o bien los conciertos del mismo o sus grabaciones. La pieza musical es el conjunto de los trazos que remiten a una unidad de dichas ocurrencias, la materialidad misma de esos trazos y finalmente la obra es el ente en su devenir, la pieza en su devenir en un lugar específico, para un observador específico y sus relaciones con todo lo que el observador "sabe que sabe" sobre la pieza. Ello es lo que llamaríamos "el ser de la pieza musical”: la obra musical de arte. Finalmente, y en términos más propios de Heidegger, la pieza y las ocurrencias concretas son parte del mundo del Dasein, en tanto que la obra como esencia es algo que menta la tierra: "Al ser de la obra pertenece el establecimiento de un mundo [... L La obra hace a la tierra adelantarse en la patencia de un mundo y mantenerse en ella"12. Jamás estaremos ciertos del límite de la obra o de poder asumir la entera dimensión de la misma. El devenir del ente pieza se nos sustrae, apareciendo de pronto para iluminar aquí y allá aspectos de una verdad que nos remite a la vida nuestra en tanto que seres.

Hasta ahora hemos marcado una distancia en la aplicación del concepto heideggeriano de obra de arte al referirlo al dominio específico de la música. No creemos, sin embargo, violentar la teoría del filósofo alemán al hacer esta reflexión. Para poder hacerla hemos aplicado sus propias categorías que, a nuestro parecer, aclaran una cuestión que en los ensayos y escritos de musicología y en la

${ }^{10}$ Heidegger 2005c: 109.

${ }^{11}$ Heidegger 2005a: 41.

${ }^{12}$ Heidegger 2005a: 76. 
crítica musical ha sido siempre muy confusa: la distinción entre obra de arte, pieza musical como unidad distinta y sus ocurrencias concretas.

Pero volvamos a Heidegger. En los escritos referidos plantea que el carácter de cosa es con lo que primero nos topamos al enfrentar una obra de arte. Ésta no es una mera cosa, si bien para el filósofo será necesario aclarar en qué medida participa la obra de la naturaleza de la cosa. A menudo se ha concebido a la cosa como modelo del ente. En la tradición filosófica podemos considerar tres tendencias: la teoría sustancialista, la teoría sensualista y la teoría "materia y forma". En el caso de la primera, la estructura de la cosa está compuesta por un sustrato permanente, invisible, y un conjunto de accidentes variables. Para la segunda teoría, la cosa es un haz de sensaciones y para la tercera la unión de una materia y una forma. Ninguna de ellas, para Heidegger, ofrece una respuesta satisfactoria. Por lo tanto, es preciso alejarse de estas concepciones para poder establecer una ontología correcta. Sin embargo, el mismo filósofo agrega que es "bastante difícil dejar ser al ente como es, sobre todo cuando tal propósito es lo contrario de aquella indiferencia que sencillamente vuelve la espalda al ente"13. No olvidemos que el ente como tal es inaccesible a la razón. Lo que trataremos de aclarar acá es si esta reticencia, en el campo específico del arte musical, pertenece a su propia esencia o deriva de un enfoque equivocado. Para Heidegger será entonces necesario discernir las diferencias esenciales y los puntos comunes entre la cosa, el útil ${ }^{14}$ y la obra de arte. Para ello utilizará el método fenomenológico, descartando en primer lugar los prejuicios tradicionales, para seguir describiendo un útil "sin teoría filosófica alguna”, en lo que se podría llamar parte constructiva del método. En el caso específico del arte esta cuestión será más compleja porque "tenderán a confundirse descripción con interpretación y fenomenología con hermenéutica"15. Esta operación la hará en los ensayos citados a partir de unos zapatos viejos de un cuadro de Van Gogh. Por este trámite descubrirá la "esencia del útil”, que no será el servir para algo sino que el "ser de confianza" (Verlässlichkeit). Esta esencia del útil nos es revelada por el cuadro, que ilumina una vida y una verdad que no era aparente. La revelación de esta verdad y esta vida es la utilidad del arte. Hacer patente la verdad del útil permite que el ente (los zapatos) aparezca en el estado de no-ocultación de su ser.

¿Qué verdad del útil revelaría la música? Mediante este ensayo trataremos de aclarar este punto. Por ahora sólo baste enunciar que la música puede ser entendida como un artefacto para evidenciar el tiempo, para engañarlo y representarlo. El tiempo como la vida ex/tendida.

Nos preguntamos a menudo cuál es el papel que juega la obra de arte en nuestra cultura y parece que ninguna definición puede cubrir enteramente este concepto. El problema es aún más complejo en el caso de la música. Contrariamente a otras expresiones artísticas, el soporte de la obra no es de naturaleza material, como en el caso de la escultura y de la pintura, sino que sufre una me-

\footnotetext{
${ }^{13}$ Heidegger 2005a: 56.

${ }^{14}$ Herramienta, utensilio, aparato.

${ }^{15}$ Heidegger: 2005a: 10.
} 
diación a través de la interpretación o ejecución bajo formas de concierto o performance.

Quizás sea útil considerar, al menos en esta reflexión, dos puntos bastante obvios: el primero es que la obra de arte musical debe ser representada o mediada a través de una ejecución, mientras que el segundo remite a que no toda música es una obra de arte.

Si bien sería teóricamente posible destruir la obra pictórica "El grito" de Munch destruyendo aquel objeto aurático y original que recibe ese nombre y que está oportunamente conservado en un lugar seguro, es bastante más complicado "destruir" la obra musical Concierto $\mathrm{N}^{\circ} 1$, para piano y orquesta, del compositor ruso Tchaikovsky. En el primer caso, si bien pueden subsistir las reproducciones y copias de la misma, ésas no podrán ser consideradas "la obra". En el segundo caso, admitiendo que fuera posible destruir todas las partituras y grabaciones del concierto, eso no anularía la posibilidad, bastante real, de que una buena cantidad de intérpretes lo conozcan de memoria (como efectivamente sucede) y lo puedan ejecutar sin la necesidad de la partitura, generando la obra o, por lo menos, haciendo imposible su destrucción. Cancelar esta obra requeriría no sólo la destrucción de los soportes materiales que permiten su ejecución, sino que también la eliminación de todos los músicos que puedan ejecutarla de memoria. Un corolario de esta consideración es que, efectivamente, una obra musical no es jamás completamente igual a sí misma, sino que depende de los aleas de la ejecución. Volveremos más adelante sobre este último aspecto, generalmente descuidado cuando se piensa en la obra de arte musical.

De esta consideración puede nacer la hipótesis de que la obra de arte musical es, por su esencia, diferente de otras modalidades de obras de arte. Cuando hablamos de que la obra de arte revela su materialidad y su propio ser ente, en verdad no podemos referirnos de la misma forma a obras de arte que son, por su naturaleza, diferentes. Debemos entonces considerar la cuestión de "la obra de arte en música” con específicos elementos teóricos.

La segunda cuestión es un poco más evidente en la experiencia cotidiana, pero las implicancias de ello escapan a menudo a los observadores y a los mismos músicos.

Las audiencias atribuyen a los objetos artísticos el papel de iluminadores, de rayos que abren espacios de nueva conciencia, social e individualmente. Pero, entonces, ¿sólo la música artística puede y debe existir? Creemos que no, dado que existen varias formas y tipos de música que son muy necesarias y convenientes, sin ser artísticas y sin pretenderlo ser, a veces. Ahora bien... ¿qué sucede con una pieza de música para que su uso social determine su calidad artística o artesanal? Para reflexionar desde la historia, podemos buscar algunos indicios en la diferencia entre Ars y Artis. El segundo término, derivado etimológicamente de la palabra latina, está dedicado a los miembros o extremidades. Artis connota aquellos productos ligados al brazo, más que a la mente, "manufacturas", en términos más actuales. El término Ars se relacionaría más a un comportamiento o "forma de hacer" que a algo físico. Las músicas de artesanía son, por así decirlo, más "manuales”, más Artis que Ars, y poseen más elementos de tipo sensible y físico que aque- 
llas obras de tipo Ars, que son más mentales. ¿Y por qué lo mental podría ser separado de lo manual? Sin compartir esa añeja división entre el brazo y la mente, no podemos dejar de notar que los productos de la mente no son tangibles y viven en la mente, en la memoria, como objetos "blandos", como productos de la observación, que, constantemente, los re-construye y al hacerlo, se reconstruye a sí misma. O sea, los productos mentales, artísticos, son construcciones ambiguas y poco tangibles, eternamente definidas en una suerte de virtualidad. El producto del brazo, Artis, artesanal, es más concreto y, de alguna manera, más "objetivo", más ligado a una noción de "objeto físico". Para cumplir esa función existencial de relacionar al ser con el mundo, el brazo manipula y opera, no en la virtualidad, sino en lo concreto. Manipula lo concreto, lo real, y para ello debe poseer una forma clara y definible más allá de toda relación con el observador. ${ }^{16}$

Son artesanales, a nuestro juicio, todas aquellas músicas que poseen esa naturaleza o modo de ser más físico, menos ambiguo, más directo y que no requieren grandes esfuerzos mentales para su decodificación. Pero, ¿por qué no requiere el mismo esfuerzo mental que una obra de tipo Ars? Simplemente, y ésta es nuestra segunda hipótesis, porque "lo físico" se presenta como "algo dado" y esto más allá de que "lo físico" sea efectivamente "ya dado" o también sea un mero objeto de representaciones mentales (o culturales). Es evidente que este tipo de "representaciones mentales", por así decir "ya dadas", presentan menos ambigüedad que las que están "por darse" y son, por ende, más simples de captar y manejar que las de tipo Ars o artísticas. Estas últimas deben, primero, con/vencer. Las artesanales, de tipo Artis, ya vencieron en su culturalidad, por ser consideradas habituales y normales. Como esta victoria es, generalmente, de tipo social, comunitaria o consensual, ya con/vencieron.

No se desea con esta reflexión reinstalar el prejuicio decimonónico contra las artes populares. Las músicas de tipo Artis o artesanales no son por tanto menos complejas, menos perfectas, menos trascendentes o menos bellas. Nada de eso. Veremos que ellas constituyen el porcentaje mayoritario entre las músicas posibles y presentes. ¿Qué ejemplos podemos citar de esas músicas? Las de tipo religioso, militar, político, de curación o sanación, bailables o de entretención, de apoyo a otras formas comunicacionales. Todos estos géneros musicales definen un espacio creativo que se definirá como "artesanal", para diferenciarlo de aquel "artístico". Artesanal, pues la preocupación de creadores y audiencias no es la de generar objetos inauditos o irremediablemente "nuevos", en todo sentido, sino que la de cumplir con ciertas funciones sociales, claramente definidas y más allá de toda ambigüedad.

Un buen objeto artesanal es insustituible y muy necesario, es además muy conveniente. Es posible pensar las mejores cosas de los artesanos y muchos grandes compositores han sido grandes y eficientes artesanos. Pero, ¿qué puede ser un

${ }^{16}$ Lo cual, estamos de acuerdo, es de todas formas una violencia a la filosofía, pues vivimos en un mundo de representaciones intersubjetivas más que de realidades concretas, pero, en fin, se entiende que el producto "mental" se re-construye cada vez que es considerado, mientras que el producto "concreto" tiene una cierta independencia del observador. 
objeto artesanal en música? Justamente un objeto útil, en términos cotidianos: una buena banda sonora para un film o un video, un bonito arreglo de una melodía para bailar o de uso corriente como sigla para un spot publicitario o un programa de TV, una bella música para acompañar juegos de agua (en época barroca) o para acompañar banquetes, etc. Es decir, son objetos que, en términos corrientes, deben ser considerados bellos y eficientes, moderados, no muy radicales ni innovadores, pero tampoco banales. No se proponen alterar la visión de mundo de quién hace uso del objeto (canción o banda sonora, música incidental), sino que otorgar un agradable espacio acústico para envolver algo... Es como un pensamiento que encuentra su molde ya listo en la realidad externa, en las constricciones de la necesidad y uso social. Sirve para algo y ello determina su forma.

Puede suceder con algunos de estos objetos artesanales que se conviertan en objetos artísticos, a veces, sin que sus creadores lo deseen, a través de su uso social. Por ejemplo, buena parte de las músicas incidentales del compositor italiano Nino Rota para los filmes de Federico Fellini pueden ser consideradas socialmente como obras de arte. En ese caso estamos ante una situación excepcional, única y rara en que dos sistemas sensibles o códigos se potencian hasta dotarlos de nuevos sentidos de conjunto. Lo mismo puede decirse de ciertas bandas sonoras de los compositores John Williams o de Ennio Morricone, pero, ¿qué tanto puede detenerse la atención del observador en una música incidental? ¿Debe su audición sobreponerse y dejar en un segundo plano las imágenes, por ejemplo? ¿Es bueno y conveniente que se recuerde la música del film y no sus imágenes narrativas? Finalmente, cuando se compra un CD con música de un film, ¿se hace para recordar el film, la emoción que éste suscitó o para recordar sólo la música?

$\mathrm{Al}$ analizar una banda incidental de una teleserie, por ejemplo, será posible definir y describir con bastante facilidad los "clichés" y estereotipos musicales con los cuales dicha música está compuesta. Ello configuraría un desastre si analizáramos esta música sólo desde el punto de vista artístico, por lo banal y obvio de sus recursos expresivos, pero constituye un éxito si la consideramos desde el punto de vista artesanal, como un refuerzo de las situaciones emotivas del video. Todos sabemos que este tipo de música más que "escucharla", se "re-escucha", se "reconoce". Para una banda incidental es fundamental que sus elementos definan, en la conciencia del auditor, lugares y espacios comunicativos ya conocidos y claros, sin crear fatiga o distraerlo del eje central narrativo. Por eso el cliché es útil y necesario, pues alude a la imagen y la connota casi sin esfuerzo decodificador (o con el menor esfuerzo posible).

¿Qué sería de las persecuciones en el cine sin ese cliché de las escalas y arpegios rapídísimos, ascendentes o descendentes, según el caso, y los glissandos? ¿Cuánto sirven a las situaciones de terror las disonancias? Aquí la música contribuye al sentido de la imagen, la refuerza y potencia. Para lograr este objetivo debe sacrificar la originalidad, pues está jugando sobre lo que el espectador conoce y aprecia, sin grandes sutilezas o ambigüedades que pudieran restarle la eficiencia descriptiva necesaria. Se trata de "caracterizar", directamente y sin preciosismos inútiles, la perspectiva emocional de lo que se está viendo y, para ello, debe "hilar grueso". No corresponde motivar en el auditor-espectador nuevas emotividades o nuevos 
modos de vivirlas, por el contrario, se trata de que ese espectador reconozca en esos estímulos sonoros (y que deben actuar en segundo plano atencional, preferiblemente) lo que ya sabe. No debe pensar demasiado ni confundirse. En este último sentido "menos es más". Algo parecido podría decirse de casi todas las músicas "artesanales" o "no artísticas": deben concurrir a llenar su objetivo social, sin parar mientes en distracciones ni acumular fatigas distractivas. Así sucede con la música bailable, tanto en Strauss como en Dj Méndez. Esa música debe hacer "bailar", tener periodicidad y rítmica clara, acompañar el movimiento y el desplazamiento espacial de forma no ambigua y, sobre todo, repetitiva y cíclica ${ }^{17}$, sus motivos melódicos deben ser cortos y claros, con arcos energéticos bien definidos, su estructura debe ser evidente, con partes que todo bailarín pueda re-conocer casi en el momento en que se producen. Finalmente, debe relacionarse formalmente con toda una categoría de piezas similares. Ningún bailarín normal estaría dispuesto a aprender un conjunto de movimientos o un baile para una sola pieza, sino que para toda una serie de ellas. Quienes sí lo harían, y lo hacen cotidianamente, son los bailarines "de arte", en el ballet, en la "danza escénica", obviamente. Y nótese que acá no estamos hablando de calidad ni de genialidad, ni de perfección, tanto menos de belleza. Es bastante normal encontrar bello (e incluso genial) el vals El Danubio azul, algunos lo encontrarán despreciable, sin duda, pero nadie se asombrará que muchas personas lo encuentren bello y, en primer lugar, los bailarines de vals.

Con todas las distancias históricas y geográficas, lo mismo podría decirse del "reggaeton" y de casi cualquier otro tipo de música danzaria, socialmente respetada. Sin embargo, parece inconveniente y errado ubicar ambas manifestaciones, respetables y dignas, en el campo de las manifestaciones de arte y todo por una equivocada democraticidad. No dejan de ser interesantes las lúcidas palabras de José Ortega y Gasset, quien en su ensayo "Musicalia" afirma lo siguiente: "Hasta ahora el espíritu democrático se ha caracterizado por una monomaníaca y susceptible ostentación de los derechos que cada uno tiene. Yo presumo que este primer ensayo de democracia fracasará si no se le completa..." ${ }^{18}$. Cuando los defensores de las músicas populares, o mediáticas, proclaman su justo derecho a ser éstas consideradas "obras de arte", olvidan que es la naturaleza de la obra la que puede determinar una diferente audición, y que esto no puede ser valorado ni como bueno, ni como malo, ni democrático, ni autoritario.

De manera similar a la música para baile podríamos hablar de la música religiosa o de la militar. En el primer caso tendremos, grosso modo, dos tipos de músicas: de meditación y de procesión. En las primeras el elemento melismático será central y la melodía se detendrá largamente sobre las sílabas del texto, generalmente sagrado o considerado como tal, demostrando la perfecta e íntima adhesión individual (por ello la posibilidad del melisma) del recitante con lo recitado. En

\footnotetext{
${ }^{17}$ Puede ser que esa última característica, la regularidad rítmica aparente, determine el uso y abuso de la batería en la música mediática. Es tan común este instrumento que he llegado a pensar que sin él, no hay música mediática, pero a lo mejor exagero....

${ }^{18}$ Ortega 1998: 238.
} 
el caso de la procesión se tratará de piezas musicales con un ritmo y un pulso marcado, por lo general binario e isocrónico, y la casi total ausencia del melisma, dado su carácter colectivo. Este último aspecto podrá ser apreciado también en las músicas militares de desfile y de marcha.

En la música incidental para audiovisuales, también es la forma la que determina su eficiencia, o mejor dicho, ciertas regularidades de forma y el uso de estereotipos. Ya podemos vislumbrar, quizás, un primer aspecto formal que va a facilitar un uso social "artesanal" de la obra musical: su regularidad y periodicidad, la simetría bilateral como paradigma del equilibrio. Entendemos por regularidad, en el caso específico de la banda sonora, un aspecto cíclico diferente respecto de la música de baile. En este caso, la regularidad opera con los efectos clichés o estereotipados que acompañan a los objetos visuales. Por ejemplo, una persecución de algún personaje será, casi siempre, caracterizada por gestos sonoros análogos a la acción visual ilustrada, acelerados o de aceleración dinámica. Estos gestos sonoros no son patrimonio de un autor o de un cineasta, salvo raros casos. Ellos constituyen un capital social, de gestos sonoros estereotipados, que un auditor medio conoce o debiera conocer. La obra en sí puede ser bella, incluso bellísima, pero estará constituida, casi obligatoriamente, por estos momentos clichés. La música ilustra y describe la acción visual, conformando un espacio acústico y emocional que envuelve el aspecto visual.

Todas estas son cuestiones que los estudiosos, y nos podemos referir a los trabajos de Michel Chion ${ }^{19}$ y de otros autores, han debatido y reflexionado en profundidad. No es éste el lugar adecuado para ahondar en esos aspectos. No obstante, si algo se puede decir acerca de estos usos de la música, es que el mensaje estético de ésta no puede anular o debilitar el soporte visual, multimedial o situacional al que va aparejada. Imagínese una discoteca en la cual los bailarines, golpeados por la belleza sonora de una pieza musical, dejan de bailar para tratar de aprehender, muy concentrados, todas las sutilezas sonoras y musicales de la misma. En este ejemplo el artesano no es tan bueno, pues la lógica dice que a la discoteca se va a bailar, a escuchar con el movimiento, a acompañar el sonido con el gesto y viceversa y no a detenerse estáticos en la contemplación maravillada de una belleza acústica. Un mal artesano podría, entonces, ser definido como un óptimo artista, ya que su producto estético re-construye el espacio de sentido de su obra, ubicándola al centro de la atención de la audiencia, hasta un punto tal, que los oyentes olvidan su calidad de bailarines. Se puede, por lo tanto, ser un pésimo artesano y un artista notable. Cada creador musical puede escoger qué papel jugar, obviamente.

En el plano artístico la obligación es la exactamente contraria. El auditor debe re-construir su modo de relacionarse con la obra cada vez que la enfrenta, para así reposicionar la consideración que tiene de su misma vida y su modo de ser. Esta re-imaginación puede ser gatillada a partir de los estímulos sonoros. Estos no pueden ser clichés, ni estereotipos, salvo en casos muy especiales de una metasignificación. El auditor debe quedar perplejo ante lo in-audito, debe detenerse e

${ }^{19}$ Chion 1997. 
interrogarse y volver a escuchar y escuchar mil veces si es necesario, para constatar que en cada nueva audición el objeto sonoro muta sus características, para ser un algo inasible y escurridizo, ambiguo y con mil sentidos. En el proceso de asir el objeto misterioso, el auditor reconstruye la imagen de sí mismo, de su mundo, renace en sí mismo, en su modo de concebir la realidad. De esta forma de ser de la obra de arte musical, Ortega nos hablaba como de una "concentración hacia fuera". Dice: "En vez de atender al eco sentimental de ella en nosotros, ponemos el oído y toda nuestra fijeza en los sonidos mismos, en el suceso encantador que se está verificando allá en la orquesta. Vamos recogiendo una sonoridad tras otra, paladeándola, apreciando su color, y hasta cabría decir que su forma. Esta música es algo externo a nosotros: es un objeto distante, perfectamente localizado fuera de nuestro yo y ante el cual nos sentimos puros contempladores" 20 .

En este caso la regularidad sólo puede nacer desde el interior de la homogeneidad de la obra en cuanto texto. No reconoce, salvo en el caso de la citación metalingüística, el uso de clichés y, claro, todo cliché conspira contra esta sustancial y esencial "novedad" des-estabilizante de lo artístico. En este sentido toda obra de arte tiene dimensiones de autorreferencialidad muy superiores a las de las obras artesanales. Si se convierte en hermetismo, ello se debe a la fatiga de audición que, normalmente, se produce cuando se enfrenta una obra de arte con la misma actitud con la que se enfrentaría una obra artesanal. La obra estética es una exploración, una aventura que nos relaciona con una verdad, no con una verosimilitud. Verdad que aparece de forma incierta, como autenticidad más que como valor lógico. Para ello la obra opera con un capital de incertidumbres, con preguntas, más que respuestas. Si se considera bella la exploración, esta música de arte puede ser bella, no ciertamente desde una armonía canónica ni en el equilibrio tradicional de su forma, o por la adecuación a moldes externos de gusto u oportunidad. Es bella pues expande los límites del género, porque desafía la comprensión y de ese modo, la amplía.

La pieza musical de arte, en su intensividad, parece nacer desde un núcleo significante homogéneo y "duro", atómico e indivisible, una especie de mínimo gesto condensado. Desde allí se proyectan y emanan las potencialidades textuales, que van articulándose y re-construyéndose en un proceso que, poco a poco, desgaja sendas hipotéticas que construyen una narración y su discurso en la memoria del auditor. Es como una cebolla que va agregando capas y capas transparentes al núcleo original, hasta configurar la superficie sensible de la cosa-pieza musical. La perfecta y adecuada homogeneidad entre superficie sensible y núcleo, es lo que parece determinar la perfección de la obra como arte. En el último análisis, es la tensión creativa y el respeto a las reglas del proceso generador que el mismo compositor se ha dado los que garantizan esta perfecta correspondencia entre superficie sensible y núcleo. Por ello un compositor no debiera "corregir", ex post, la superficie textual de su pieza musical, ya que haciéndolo atenta contra su propio sistema, su propia coherencia. El compositor enuncia el núcleo, como una transfiguración intensiva de la complejidad de la vida. El análisis de las poten-

${ }^{20}$ Ortega y Gasset 1998: 243. 
cialidades expresivas del núcleo parece determinar conjuntos de reglas que articulan procesos de tomas de decisiones, que descartan y eligen elementos lingüísticos y sonoros y sus relaciones recíprocas. Dichos procesos entonces podrían generar la superficie sensible, lo que es comunicado al auditor e intérpretes (ejecutantes) a través de performances -ejecuciones- y programas de ejecución -partituras- respectivamente.

La pieza musical artesanal procede en sentido inverso, pues debe adecuar su existencia a lo ya sabido, de manera determinística, pues nace del cliché, de la regularidad, de la ciclicidad, de lo reconocible y de lo adecuado a su función de uso. Una música de baile debe, antes de todo, permitir bailar. Es bella, pues procede desde su apariencia, desde una belleza sensible, construida por la regularidad y simetría de las formas, en el respeto del canon y la norma socialmente aceptada. Desde esa superficie sensible, que debe ser considerada adecuada al uso y agradable, se construye la pieza musical artesanal hacia su interior. No necesariamente tiene un núcleo interno generador, sino que su construcción se explica desde su superficie. En algunos casos notables (y no son tan pocos) la inventiva o sensibilidad del artesano creador logra definir, gracias a su genialidad intuitiva, por ejemplo, un núcleo que, desde el interior de la pieza, da una nueva coherencia y homogeneidad al producto final. Recordemos que ya existe una homogeneidad asegurada a nivel de la superficie sensible por el uso de recursos estilísticos coherentes, de estereotipos del género, que el artesano creador define desde su oficio y conocimiento del uso y práctica social. Por así decirlo, es el contexto que le da significado, y la perfecta adecuación al mismo, la que asegura la eficiencia de la pieza musical artesanal.

Como se puede ver, también en este caso es el "oficio" lo que determina la acabada construcción y eficiencia del producto. Más sabe el artesano-creador y mejor construye su pieza musical. Creemos que ésta sí que es una música "docta" o "académica", pues nos parece más respetuosa del canon y de la tradición de cuanto no lo deba ser la música de arte. Obviamente el compositor de arte debe conocer su oficio, pero no puede limitarse a una aplicación del canon o de la tradición. El artista debe crear "algo" nuevo, intenso e in-audito. En este sentido el compositor podría ser definido como un "auditor insatisfecho", que compone lo que le habría gustado escuchar, pero que nunca había podido oír de esa determinada manera.

¿Qué comunica el artesano? El artesano comunica una superficie sensible o texto, como cruce de códigos coherentes, que puede o no tener un núcleo significante, ya que su significación última descansa en el contexto.

¿Qué comunica el artista? Debiera comunicar un "texto como innovación" al contexto, a todo lo que él sabe que el auditor medio conoce. El compositor, como artista, no escribe una sonata para crear un "objeto de uso sonático" sino que, si el caso lo determina, su sonata debe aparecer como una innovación y deconstrucción de todas las sonatas ya escritas. Como una nueva forma de ver la "sonata", una sonata in-audita, una sonata cuya coherencia es decir, "sonatísticamente", una nueva forma de "ser sonata". Esta operación improbable re-construye y desestabiliza las costumbres auditivas y culturales del auditor. Al negar la realidad aparente y habi- 
tual, le permite re-construir su vida, la imagen de sí mismo, negando el cliché y demostrando el carácter ideológico del mismo, en el que la "ideología" es la negación de la vida, pues consagra un solo discurso como el único viable, como la única representación posible de lo creado. Toda ideología supone una negación de la vida, en tanto la vida pueda definirse como una deriva, como una exploración y un di-vagar entre posibles representaciones del mundo, como una di-versión. La vida es fuente inagotable de nuevas maneras de ver el mundo y para ello depende de la calidad reconstructiva de la conciencia que se produce en la duda y en la exploración. Es posible formular la hipótesis que para eso sirva el arte, para aprender a desobedecer. Para re-nacer negando todo lo que ya sabemos, sabiendo que lo sabemos. Para afirmar que siempre es posible ser otro, y de otra manera.

Puestas así las cuestiones, aparece la imposibilidad de concursos de música de arte. ¿Cómo pueden confrontarse composiciones tan proteicas? ¿Tan singulares que cada vez que son oídas cambia su percepción? Ello permitiría formular la hipótesis acerca de la inutilidad de los concursos y festivales especializados con jurados y comisiones de selección. Lo que allí se elige generalmente son perfectas piezas musicales artesanales que imitan piezas artísticas, cuya función es, justamente, aparecer como una obra "artística”, intelectual. De ahí surgen los estereotipos de la música contemporánea, los perfectos y, a veces, bellos productos artesanales que parecen artísticos. O sea, el diablo que habíamos cazado por la puerta, entró por la ventana... Es difícil creer en los jurados para la producción de arte, en las comisiones de selección. ¿Qué criterios usan para juzgar algo que es irremediablemente "nuevo" e insólito? Es precisamente por esa novedad que deviene Ars: lo nuevo, lo in/audito.

¿Cómo puede hacer esta re-construcción del sí mismo una obra de arte musical? ¿Qué relaciona la superficie sensible con su núcleo? Es prácticamente imposible responder de una vez y para siempre a esta pregunta, puesto que los artistas están probando, y es justamente ese probar que los define como tales. Es relativamente más simple constatar cuando una obra de arte falla en su intento. Una pieza musical de arte se destruye a sí misma y a su "nueva edad" haciendo que la obra se adecue a los moldes externos, se convierta en artesanía. Inversamente, una obra artesanal falla en su intento cuando el usuario olvida la función principal que lo convocaba, como bailarín, fiel, devoto, peregrino, soldado, desfilante, espectador y se convierte en un simple auditor, capturado por lo in-audito de la experiencia.

\section{TEMA DOS}

¿Pero es la obra en cuanto ser una cuestión abstracta? ¿Un modelo abstracto de relaciones entre texto y contexto que puede presidir a sus manifestaciones concretas? ¿Es la obra una idea? La visión de Heidegger nos aleja de cualquier idealismo estético, para el cual una obra de arte es una suerte de idea mental, espiritual, una especie de intuición, modelo abstracto cuya materialización objetiva es sólo un hecho accesorio.

De lo que hemos expuesto hasta acá, la materialidad de la obra de arte pudiera aparecer sólo como un soporte físico, como una característica del ente-pieza y 
que no contamina su ser, modelo ideal. Sin embargo, si seguimos atentamente el razonamiento del filósofo veremos que esta cosidad tiene un valor estético propio. Es justamente a través de su manifestarse en la obra que se devela la lucha que presentan el mundo y la tierra, pues el mundo tiende a hacerse patente, a exponerse, en tanto que la tierra tiende a sustraerse y lo propio de la obra es presentarla, constituyendo un tipo de mundo que permite que el hombre haga de esa tierra su morada.

Hay además otras razones que anclan al ser del ente, la obra a la materialidad, y evitan toda abstracción idealista.

En la idealización estos modelos abstractos se presentan como cosas, como entes que niegan el devenir. Como si fuera posible situarse más allá del tiempo de observación y de todo posible espacio, justamente en la abstracción, para, idealmente y como dioses inmortales, comparar substancias eternas. Sabemos que ello no es posible. Si el concepto de modelo abstracto para definir la obra remite sólo a su imposibilidad de manejo concreto, podríamos entonces concordar con las categorías idealistas. No obstante la obra, por muy modelo abstracto que sea, evidencia la imposibilidad de su consideración completa, cabal y total. No somos dioses y nuestras observaciones no son generales, sino que muy específicas y, en este sentido, todo modelo abstracto se nos sustrae en su devenir. Entonces, el concepto de modelo, aunque sea abstracto, no puede servirnos para hablar de la obra, que es fundamentalmente devenir. Una obra se sustrae al observador, pues, en la medida que éste genera un posible modelo explicativo, está afirmando la unicidad de su propia observación, tanto en el tiempo como en el espacio. Por muy perfecto que sea el modelo que el observador construye para sí en la obra, no obstante su coherencia interna, por muy complejo y profundo que el modelo explicativo sea, contiene siempre en sí el germen de su sustancial inutilidad: la inevitable coyunturalidad y especificidad de su observación.

No existen modelos explicativos eternos así como no pueden existir observadores eternos, más allá del tiempo y el espacio, trascendentes. La obra de arte sólo puede ser trascendente, a su época y espacio, en la medida que sigue constituyendo, a veces por circunstancias bastante fortuitas, una referencia nominal para observar y construir modelos explicativos. No obstante, ¿se puede decir que estamos siempre hablando de la misma obra?... Sí y no. Afirmativamente, en cuanto la obra, sustrayéndose a la observación siempre coyuntural y al modelo explicativo que ésta genera, conserva en su propia sustracción una fuente de misterio y de reconstrucción, de novedad para posteriores observaciones. Negativamente, en cuanto la obra nos es constantemente velada por sus ocurrencias concretas, las que justo en el momento en que se revelan en un tiempo y espacio dados, para un observador dado, están velando y sustrayéndonos la obra misma, dada su naturaleza. Este proceso de aparecer y a la vez sustraerse, siendo velada por la cosidad de la ocurrencia concreta, este ocultamiento de las relaciones que la obra contiene en su seno, guarda relación con el hecho de que la pregunta por la obra en realidad no se dirige a un entidad concreta, sino que a la misma forma de ser del arte. La obra es verbo, es acción: es la modalidad específica del ser del arte, más allá de toda apariencia concreta, de toda sustantivación o adjetivación. La obra no puede 
ser revelada en el inventario de los rasgos distintivos de sus ocurrencias concretas, tampoco en el análisis de las relaciones entre dichos trazos, por profundo que éste pueda ser. La pregunta por la obra es la pregunta por el ser, por el devenir del arte como aparición y sustracción, como afirmación y negación de lo ex/sistente. En este último aspecto, la pregunta por la obra no puede jamás ser plenamente satisfecha, ya que comportaría poder considerar la casi infinita red de relaciones que la obra presenta, con todo lo que sabemos que pudo estar allí y no estuvo y todo aquello que sí estuvo, pudiendo no haber estado. Todo ello constituyéndose en un momento específico, para un auditor específico, en el instante mismo de su percepción.

Cuando consideramos una sonata específica como obra de arte, cuando dirigimos la preguntas hacia su "ser como obra", estamos aludiendo a toda la casi infinita red de relaciones que dicha obra sonata presenta, con todo aquello que sabemos que pudo "ser" en esa obra. Obviamente, debemos también considerar que de "esa sonata" no podemos realmente hablar sino que como experiencia de su ocurrencia concreta, en cuanto nosotros mismos, como observadores, no somos más que instantes coyunturales y específicos. La sustracción opera por toda esta suma de imposibilidades y de especificidades. La tal sonata no se nos revela más que como rasgos distintivos en ocurrencias concretas, para observadores muy instantáneos y limitados en el tiempo y el espacio como para poder afirmar algo más que sorpresa. Sin embargo, y más allá de estas especificidades, estos rasgos distintivos remiten a una sustancial homogeneidad de todas sus ocurrencias. Esto quiere decir que más allá que una grabación sea de una materialidad muy diferente a una partitura, sus rasgos distintivos remiten a la unicidad de la música a la que ellos refieren. Esta unicidad es la pieza musical. La VSinfonía de Beethoven es conocida como tal y percibida como tal más allá de las diferencias materiales entre sus ocurrencias concretas y esto sucede pues sus rasgos distintivos remiten a una homogeneidad y unicidad. Esta homogeneidad no reposa en un modelo abstracto o "idea", sino que en la materialidad misma de la pieza. Los rasgos distintivos, materia pura, presentan analogías e iconicidades entre las diferentes agrupaciones materiales que son sus ocurrencias. La grabación dura lo que debiera durar una lectura media de la partitura y así para las relaciones entre sus melodías, notas, y timbres. No es el sonido la base material de la pieza, sino que la unicidad y homogeneidad entre sus trazos distintivos, en la suma de sus ocurrencias. La pieza musical, como ente, es la sede de esta unicidad material, matérica. Es la coseidad de la pieza musical la que unifica sus ocurrencias concretas como pertenecientes o derivadas de la misma pieza musical.

La obra de arte no es la pieza y no depende de esta materialidad, sino que se presenta y sustrae por encima (o debajo) de ésta. La obra, como devenir, es apenas "vista" o percibida por el auditor como una potencia, de la cual no existe jamás certeza. Sin embargo, su existencia y su develarse instantáneo iluminan la pieza musical con la certidumbre de la verdad. La obra es el ser que aparece para revelar la verdad del arte, esto es, que el arte está hecho de la misma substancia que la vida: puro devenir, que no es artificio, sino que manifestación de unicidad y plan. 
En esta instantánea aparición, la obra, como modelo abstracto y virtualmente inalcanzable, nos fulgura con la luminosidad de sus relaciones aparentes y con su íntimo relacionarse con todo lo que ya sabemos e ignoramos. Es lo propio del ser de la obra: la eterna sustracción, luego de hacernos intuir su presencia, a través de sus ocurrencias concretas. ¿Pero esta obra habita el espacio de lo sagrado, el tiempo de los dioses para revelársenos cual iluminación esotérica? No, la obra habita el muy pequeño y siempre cambiante tiempo del ser, que constituimos con toda la suma de nuestras especificidades puestas en juego. Es precisamente, dado que somos limitados y coyunturales, que la obra es inalcanzable, pues ésta habita justamente este devenir que es nuestra especificidad, este constante nacer y morir que son nuestros instantes. Más que estar en el tiempo-sin-tiempo de los dioses, la obra existe en el infinito relacionar/se de nuestros pequeños y muy limitados lugares de existencia. Existiendo entre el auditor, los auditores y el creador, en sus infinitos tiempos y lugares de relaciones infinitamente pequeños, la obra se expande en el lugar del ser, en el ser del arte, devenir y no entidad. La obra en cuanto ser nos remite a nuestra propia existencia como seres. Si la pieza musical nos relaciona con su propia entidad en su forma material de ente, si por ello afirma su naturaleza de cosa, manifestada por diferentes ocurrencias concretas y caracterizadas por sus trazos materiales analógicos y distintivos, la obra es el ser de ese ente, que nos habla de nuestro ser, de nuestra forma de existir como ser.

Una pieza musical artesanal también posee ocurrencias concretas como reflejo de un modelo abstracto, "obra" en sentido estricto. Dicha obra también es el producto de una intersección entre un texto y un contexto. Pero, en este caso, las reglas de la construcción no proceden de un núcleo, ni tanto menos son objeto de decisiones autónomas del creador, sino que deben operar sobre el respeto de los contextos de uso. La eficiencia de la pieza musical está dada justamente por ese respeto a las reglas contextuales. El texto es una variación en las normas del contexto, y no $a$ las normas del contexto. Aparece el texto como una innovación coyuntural, específica, y que tiende a confundirse con la ocurrencia concreta. Este conjunto de innovaciones "en -y dentro de- las normas" permite una cierta deriva y mutación del género y de sus normas contextuales, pero con una gran inercia y persistencia de los modelos tradicionales. Por eso es posible la llamada "licencia creativa" y la gratuidad de las decisiones composicionales no son tan críticas, ya que es la normativa contextual la que asegura la coherencia del producto dentro de su género. Las innovaciones y licencias deben respetar la costumbre y son la excepción que confirma la regla. Alejarse mucho de ella significaría la incomprensibilidad y la inexistencia de regularidades que aseguren su decodificación. Este último aspecto, que es una ventaja en la música de arte, en la que el objetivo es re-construir una manera de hacer, constituye una deficiencia para la música artesanal, en la que el objetivo es reposicionar los estereotipos de uso de manera adecuada.

¿Pero está presente la obra y bajo qué formas en la pieza musical artesanal? También en este caso el observador es uno y múltiple, coyuntural y específico, limitado en cuanto tiempo y espacio con la obra como potencia, como cuasi infinita red de relaciones. ¿Pero la atención del observador hacia dónde se dirige? 
¿Constituye su auditar una aventura improbable como en la experiencia estética?, $\mathrm{o}$ ¿es más bien el inventario de congruencias y persistencias?

La audición del observador parece acá dirigirse hacia lo constante, hacia lo colectivo, hacia lo estable asegurado por la sensibilidad de ser un corpus genericus. Esta sensibilidad se afirma en el cliché, en el reconocer y limitar su experiencialidad a lo evidente, a lo aparente.

Como en el caso de la obra de arte musical, la ocurrencia concreta, la suma de los trazos distintivos vela la sustancial esencia de la obra artesanal en cuanto infinita red de relaciones, pero en la pieza de música artesanal la atención no está puesta en lo fugitivo, como suma de trazos aparentemente contradictorios, lo inefable, sino en lo aparente, definitorio. No importa que en realidad esta apariencia sea sólo "aparente", puesto que en esa apariencia reposa lo significativo para el observador artesanal. El ser de esta obra artesanal es justamente este "aparecer" y su "devenir aparente" es lo propio de su ser.

La innovación, como carácter propio del ser de la obra de arte, se sustrae, en cuanto devenir, para cosificarse en dificultad de decodificar el cliché y, por ende, en fatiga atencional. Por esta última razón la música de arte genera esa fatiga de audición, tan típica de la música experimental y de vanguardia y de la que tanto se quejan los auditores acostumbrados a una sola práctica estética: aquella propia de la música artesanal, tan común en el medio musical actual.

No interesa la ruptura, la interrupción del discurso que pudiera constituir ese momento de sorpresa y perplejidad. Acá lo que mueve, lo que determina al observador es justamente este sobrevolar sobre la rugosidad y especificidad de las apariencias del devenir, para concentrar la atención sobre lo estable. No es el instante lo que capta la atención del auditor de la pieza de música artesanal, sino la constatación de ese devenir como flujo monocorde, siempre igual a sí mismo, al cliché, a la función que lo convoca. Así como la pieza de música artesanal parece construirse desde afuera hacia adentro y la pieza musical artística en sentido inverso, también la atención sobre la obra, como potencia y modelo abstracto de lo musical, parece proceder en sentido inverso. En el caso de la obra, considerada por el observador en su ser artístico, es constante sustracción y velamiento por la incumbencia detallada de trazos concretos, ocurrencias que en su improbabilidad y aparencialidad, esconden el devenir de la casi infinita red de relaciones. Es casi como que el constante descentramiento que provoca este fluir inefable impidiera coger el movimiento de su aparecer, provocando simultáneamente más paradojas que certidumbres. En el caso de la obra considerada por el observador como artesanía, el detalle de su aparecer no interesa, en cuanto no es más que la granulosidad de un devenir ya sabido o intuido, por la práctica del cliché como elemento ordenador. Al observador no le interesa su propio ser específico, en cuanto punto único e irrepetible del experenciar, sino que su realidad como sentir colectivo. Más allá del detalle percibido, la perfecta o casi perfecta alineación del ser de la obra artesanal con lo ya sabido y esperado. Así la atención se concentra en su devenir y no en el detalle. También acá es aparente una cierta forma de sustracción de la obra como verdad del ser, pero únicamente en cuanto el modelo abstracto de la obra determina a las ocurrencias concretas, no sólo en términos 
generales, sino que en sus instantes concretos y específicos. Pero esto no interesa a la observación de lo artesanal, pues lo que importa es la apreciación del conjunto de los trazos, como trazos pertinentes al devenir como obra artesanal. De hecho, el trazo, en cuanto tal, podría decirse que se sustrae velado por la incumbencia de la categoría (el cliché) como objeto de la atención. Entonces se produce la paradoja que ese trazo aparente, esa superficie que constituyó el punto de partida para la creación artesanal se sustrae para el observador, reemplazada por el devenir del cliché. El aspecto superficial y de detalle, que fue determinante para el creador artesano, desaparece en la percepción del cliché y de su adecuación a la función social del producto musical artesanal. Es así como lo ya sabido caracteriza la audición de la obra musical en cuanto artesanía.

Nada de esto tiene que ver con la calidad, ni con la dignidad del producto. Una buena pieza musical artesanal, bien hecha, con inspiración e ingenio, es preferible a una composición musical que se desea artística, pero que finalmente se presenta como un producto manierista que, en vez de presentar transparentemente el cliché propio de la artesanía, emula, sin confesarlo, los clichés de un objeto "artístico", "experimental" o "contemporáneo". Esto configura una práctica artesanal que esconde su nombre y por ende produce un pseudoarte.

\section{CODA Y CONCLUSIÓN}

Muchas veces se ha limitado la idea de "artista" al modelo de la estética romántica: un ser retraído, aislado y tocado por la "inspiración”, un demiurgo de sentidos arcanos y lejanos, que expresa su caótico y atormentado mundo interior. Hoy en Chile es la idea corriente y dominante en los conservatorios y clases de composición. Pero esa es una idea que ya tiene demasiados años como para ser válida y fresca, vital... desde el siglo XIX, por lo menos. También esa idea romántica del artista va ligada a un sentido evolutivo a la Darwin, propio del mecanicismo del siglo XIX, en el que la historia de la música es una sucesión de etapas de desarrollo creciente. Una consideración más atenta de la historia de la música hace aparecer lo musical como generado por una deriva casi natural y como fruto de las contradicciones, más que por un plan evolutivo.

La visión del artista como un demiurgo de una "música absoluta", que realiza una intuición genial, propia del idealismo romántico, consagra una división entre una música "alta", absoluta y una "baja", la popular o comercial, la filistea. Creemos que las consideraciones de Heidegger sobre la obra de arte permiten aclarar la naturaleza de la producción de sentido en el arte. Hemos podido aplicar esas fecundas ideas para reflexionar sobre la música artesanal o artística, desde su materialidad y no como correlato de "inspiraciones abstractas". No como manifestaciones musicales "bajas" o "altas", ni tampoco como prejuicios ideológicos. Una ontología de la obra de arte musical debe cumplir esta función de determinar cómo procede el ser del ente musical, más allá de todo idealismo.

Para poder situar esta comprensión del ser de la obra musical como artística o como artesanal, es necesario comprender que la obra musical no se comporta como las otras obras de carácter artístico. Así hemos necesitado definir lo que 
llamamos "pieza musical", que es el modelo que preside todas las manifestaciones de la música: grabaciones, conciertos, partituras o cualquier otra referencia concreta o manifestación de lo musical. Esto es lo que Eco llamaría "ocurrencias concretas". Entonces la pieza musical es una cosa, un ente, que preside a las manifestaciones diversas de sí mismo, a sus representaciones. Pero "la obra" debe ser otra cosa y no puede ser algo definido o una cosa, sino que es el ser de la pieza musical como ente. La obra es ese específico modo de ser que tiene una pieza y que la califica como lo que es para los observadores. Actúa y está presente al momento de las ocurrencias concretas que manifiesta la pieza musical como entidad para los observadores, pero no es la pieza ni sus ocurrencias, es algo de otra naturaleza, es una potencia. Pero no toda pieza musical es artística, más parece que éstas sean la excepción y que la norma sea constituida por piezas musicales que hemos definido como artesanales. Ambos tipos de piezas musicales están constituidas por diferentes naturalezas y estas naturalezas son diferentes desde su materialidad, pues cumplen diferentes funciones y ello gracias a su propia materialidad. Asimismo, su ser es diferente, justamente desde su materialidad y su construcción pone en evidencia este diferente ser. No en cuanto culturas "bajas" o "altas", sino que en cuanto obras diferentes.

\section{BIBLIOGRAFÍA}

Chion, Michel

1997 La música en el cine. Traducción de Manuel Frau. Edición original, La Musique au cinema, Ed. Fayard, 1985. Barcelona: Ed. Paidós.

Heidegger, Martín

2005a "El origen de la obra de arte", Arte y Poesía. Traducción Samuel Ramos. Edición original, Der Ursprung des Kunstwerkes, 1952-1980. Primera edición en español 1958. Duodécima reimpresión. México: Ed. Breviarios del Fondo de Cultura Económica México, pp. 37-123.

2005b Ser y Tiempo. Traducción de Jorge Eduardo Rivera. Edición original, Sein und Zeit, versión 1972. Santiago: Editorial Universitaria. Cuarta edición.

2005c Qué significa pensar. Traducción de Raúl Gabás. Edición original, Was heibt denken, 1997. Madrid: Ed. Trotta.

Ortega y Gasset, José

1998 "Musicalia”, El Espectador III (1921), Obras Completas. Volumen II. Tercera reimpresión. Madrid: Ed. Alianza, pp. 235-244.

2007 "Impopularidad del arte nuevo", La deshumanización del arte. Primera edición, 1987. Decimocuarta edición. Madrid: Ed. Austral/Espasa Calpe, pp. 45-49.

Vattimo, Gianni

2006 Introducción a Heidegger. Traducción de Alfredo Báez. Edición original, Introduzione a Heidegger, Ed. Laterza. Cuarta reimpresión. Barcelona: Ed. Gedisa. 